\title{
Human synapses show a wide temporal window for spike-timing-dependent plasticity
}

\section{Guilherme Testa-Silva ${ }^{1+}$, Matthijs B. Verhoog ${ }^{1+}$, Natalia A. Goriounova ${ }^{1+}$, Alex Loebel ${ }^{2}$, J. J. Johannes Hjorth ${ }^{1}$, Johannes C. Baayen ${ }^{3}$, Christiaan P. J. de Kock ${ }^{1}$ and Huibert D. Mansvelder ${ }^{*}$}

\author{
Department of Integrative Neurophysiology, Center for Neurogenomics and Cognitive Research, VU University, Amsterdam, Netherlands \\ 2 Division of Neurobiology, Department of Biology II, Ludwig-Maximillians University Munich, Munich, Germany \\ ${ }^{3}$ Department of Neurosurgery, VU University Medical Center, Neuroscience Campus Amsterdam, Amsterdam, Netherlands
}

\section{Edited by:}

Per Jesper Sjöström, University

College London, UK

Reviewed by:

Yang Dan, University of California,

Berkeley, USA

Johannes J. Letzkus, Friedrich

Miescher Institute for Biomedical

Research, Switzerland

Laurent Venance, Collège de France,

France

\section{${ }^{*}$ Correspondence:}

Huibert D. Mansvelder, Neuroscience

Campus Amsterdam, Center for

Neurogenomics and Cognitive

Research, De Boelelaan 1085, 1081 HV

Amsterdam, Netherlands.

e-mail: huibert.mansvelder@cncr.vu.n

${ }^{\dagger}$ Guilherme Testa Silva, Matthijs B. Verhoog, and Natalia A. Goriounova have contributed equally to this work.
Throughout our lifetime, activity-dependent changes in neuronal connection strength enable the brain to refine neural circuits and learn based on experience. Synapses can bi-directionally alter strength and the magnitude and sign depend on the millisecond timing of presynaptic and postsynaptic action potential firing. Recent findings on laboratory animals have shown that neurons can show a variety of temporal windows for spike-timing-dependent plasticity (STDP). It is unknown what synaptic learning rules exist in human synapses and whether similar temporal windows for STDP at synapses hold true for the human brain. Here, we directly tested in human slices cut from hippocampal tissue removed for surgical treatment of deeper brain structures in drug-resistant epilepsy patients, whether adult human synapses can change strength in response to millisecond timing of pre- and postsynaptic firing. We find that adult human hippocampal synapses can alter synapse strength in response to timed preand postsynaptic activity. In contrast to rodent hippocampal synapses, the sign of plasticity does not sharply switch around 0-ms timing. Instead, both positive timing intervals, in which presynaptic firing preceded the postsynaptic action potential, and negative timing intervals, in which postsynaptic firing preceded presynaptic activity down to $-80 \mathrm{~ms}$, increase synapse strength (tLTP). Negative timing intervals between -80 to $-130 \mathrm{~ms}$ induce a lasting reduction of synapse strength (tLTD). Thus, similar to rodent synapses, adult human synapses can show spike-timing-dependent changes in strength. The timing rules of STDP in human hippocampus, however, seem to differ from rodent hippocampus, and suggest a less strict interpretation of Hebb's predictions.

Keywords: human, synapse, hippocampus, neocortex, synaptic plasticity, spike-timing-dependent plasticity, Hebbian plasticity

\section{INTRODUCTION}

One of the central questions in neuroscience is how memories are formed and stored in the human brain. From a large number of studies on laboratory animals it is known that learning and memory are most likely mediated by activity-dependent neuronal circuit modifications resulting from synaptic plasticity (Bliss and Lomo, 1973; Cooke and Bliss, 2006; Whitlock et al., 2006; Letzkus et al., 2007). The ability to shape neuronal connections in an activitydependent manner enables the brain to functionally refine neural circuits in response to sensory experience and adapt to changing environments (for review see Caporale and Dan, 2008). In line with predictions made by Hebb (1949), synapse strength can be modified depending on the millisecond timing of action potential firing and the sign of synaptic plasticity depends on the spike order of presynaptic and postsynaptic neurons (Levy and Steward, 1983; Gustafsson et al., 1987; Bell et al., 1997; Magee and Johnston, 1997; Markram et al., 1997). By varying the timing and order of preand postsynaptic spiking, it was found that critical time windows exist for synaptic modification on the order of tens of milliseconds (Bi and Poo, 1998, 2001). In recent years, it has become clear that diversity exists of temporal windows for spike-timing-dependent plasticity (STDP) depending on parameters such as brain area and neuron type (Froemke et al., 2005; Wittenberg and Wang, 2006; Meredith et al., 2007; Caporale and Dan, 2008). However, it is unknown what synaptic learning rules exist in human synapses and whether similar temporal windows for STDP at synapses hold true for the human brain.

There are few studies on synaptic LTP and LTD in humans. With field potential recordings from hippocampal and neocortical tissue excised from human patients it was shown that high frequency stimulation $(100 \mathrm{~Hz})$ induces LTP in human synapses (Chen et al., 1996; Beck et al., 2000). Blocking NMDA receptors with APV prevents LTP induction, indicating that plasticity of human synapses shares molecular mechanisms with animal models. Low frequency stimulation $(1 \mathrm{~Hz}$ ) resulted in LTD (Chen et al., 1996), showing that the strength of human synapses can be regulated bidirectionally. Indirect evidence suggests that coincident millisecond timing of activity is likely to govern synaptic changes in humans as well (Stefan et al., 2000; Wolters et al., 2003). Pairing transcranial magnetic stimulation (TMS) of motor cortex with peripheral nerve stimulation in vivo can alter motor-evoked potentials in muscles, and precise timing determines the sign of this plasticity (Wolters 
et al., 2003, 2005). Timed TMS of motor cortex and peripheral stimulation may induce synaptic plasticity in cortical circuits, but a direct demonstration thereof is lacking. In this study, we set out to directly test whether human synapses can alter strength in response to millisecond timing of pre- and postsynaptic firing. In addition, we explored the temporal window for STDP at these synapses. We find that in contrast to rodent hippocampus, adult human hippocampal synapses show a wide temporal window for STDP.

\section{MATERIALS AND METHODS HUMAN HIPPOCAMPAL SLICE PREPARATION}

All procedures on human tissue were performed with the approval of the Medical Ethical Committee of the VU University Medical Center and in accordance with Dutch license procedures and the declaration of Helsinki. Human slices were cut from hippocampal tissue that had to be removed for the surgical treatment of deeper brain structures for epilepsy with written informed consent of the patients (aged 20-66 years) prior to surgery. Anesthesia was induced with intravenous fentanyl $1-3 \mu \mathrm{g} / \mathrm{kg}$ and a bolus dose of propofol $(2-10 \mathrm{mg} / \mathrm{kg}$ ) and was maintained with remyfentanyl $250 \mu \mathrm{g} / \mathrm{kg} /$ min and propofol $4-12 \mathrm{mg} / \mathrm{kg}$.

After resection, the hippocampal tissue was placed within $30 \mathrm{~s}$ in ice-cold artificial cerebrospinal fluid (ACSF) slicing solution which contained in (mM): 110 choline chloride, $26 \mathrm{NaHCO}_{3}, 10$ D-glucose, 11.6 sodium ascorbate, $7 \mathrm{MgCl}_{2}, 3.1$ sodium pyruvate, $2.5 \mathrm{KCl}, 1.25 \mathrm{NaH}_{2} \mathrm{PO}_{4}$, and $0.5 \mathrm{CaCl}_{2}-300 \mathrm{mOsm}$. (Bureau et al., 2006) and transported to the neurophysiology laboratory, which is located within $200 \mathrm{~m}$ distance from the operating room. The transition time between resection of the tissue and the start of preparing slices was less than $15 \mathrm{~min}$.

Hippocampal slices $(300 \mu \mathrm{m})$ were prepared in ice-cold slicing solution, and were then transferred to holding chambers in which they were stored for $30 \mathrm{~min}$ at $34^{\circ} \mathrm{C}$ and for $30 \mathrm{~min}$ at room temperature before recording in ACSF which contained (in $\mathrm{mM}$ ): $\mathrm{NaCl}$ 125; KCl 3; $\mathrm{NaH}_{2} \mathrm{PO}_{4}$ 1.25; $\mathrm{MgSO}_{4} 2 ; \mathrm{CaCl}_{2} 2 ; \mathrm{NaHCO}_{3} 26$; glucose 10 , bubbled with carbogen gas $\left(95 \% \mathrm{O}_{2} / 5 \% \mathrm{CO}_{2}\right)$.

\section{ELECTROPHYSIOLOGY}

Hippocampal slices were visualized using either infrared differential interference contrast (IR-DIC) microscopy or Hoffman modulation contrast. After the whole cell configuration was established, membrane potential responses to steps of current injection were used to classify each cell electrophysiologically. Cells were loaded with biocytin through the recording pipette for post hoc identification. All experiments were performed at $32-35^{\circ} \mathrm{C}$. Although the hippocampal tissue was resected from the brains of epilepsy patients, none of the neurons recorded from showed spontaneous epileptiform spiking activity. Resting membrane potentials were in line with previous reports on recordings from human neurons $(-64 \pm 5 \mathrm{mV}$ for Pyramidal and $-65 \pm 7 \mathrm{mV}$ for Non-pyramidal cells). All experiments were performed in the absence of blockers of GABAergic synaptic transmission.

Recordings were made using Multiclamp 700A/B amplifiers (Axon Instruments, CA, USA) sampling at intervals of 50 or $100 \mu \mathrm{s}$, digitized by the pClamp software (Axon) or custom written scripts in Igor Pro, and later analyzed off-line using custom written Matlab scripts (Mathworks). Whole cell current injection and extracel-
Table 1 | Summary table of action potential properties.

\begin{tabular}{lcl}
\hline & $\begin{array}{l}\text { Pyramidals } \\
(\boldsymbol{n}=\mathbf{9})\end{array}$ & $\begin{array}{l}\text { Non-pyramidals } \\
(\boldsymbol{n}=\mathbf{7})\end{array}$ \\
\hline First AP amplitude $(\mathrm{mV})$ & $113.8 \pm 8.0$ & $114.5 \pm 2.3$ \\
Second AP amplitude $(\mathrm{mV})$ & $115.7 \pm 4.8$ & $111.9 \pm 1.6$ \\
First AP upstroke $(\mathrm{mV} / \mathrm{ms})$ & $231.3 \pm 38.4$ & $147.0 \pm 14.2$ \\
Second AP upstroke $(\mathrm{mV} / \mathrm{ms})$ & $207.3 \pm 28$ & $119.1 \pm 10.7$ \\
First AP downstroke $(\mathrm{mV} / \mathrm{ms})$ & $99.2 \pm 8.3$ & $103.3 \pm 2.7$ \\
Second AP downstroke $(\mathrm{mV} / \mathrm{ms})$ & $74.3 \pm 16.5$ & $83.3 \pm 2.4$ \\
First AP half-width (ms) & $1.1 \pm 0.2$ & $1.03 \pm 0.04$ \\
Second AP half-width (ms) & $1.3 \pm 0.1$ & $1.23 \pm 0.03$ \\
Max ADP avg (mV) & $11.3 \pm 0.6$ & $12.6 \pm 0.4(n=1)$ \\
Tau ADP avg (ms) & $16.6 \pm 1.2(n=7)$ & $20.3 \pm 2.3(n=1)$ \\
\hline
\end{tabular}

Data presented as mean (absolute values) \pm S.E.M.

lular stimulation (both timing and levels) were controlled with a Master-8 stimulator (A.M.P.I., Jerusalem, Israel) triggered by the data acquisition software. Patch pipettes (3-5 M $\Omega$ ) were pulled from standard-wall borosilicate capillaries and filled with intracellular solutions containing (in mM): K-gluconate 140; KCl 1; HEPES 10; K-phosphocreatine 4; ATP-Mg 4; GTP 0.4, pH 7.2-7.3, pH adjusted to 7.3 with $\mathrm{KOH} ; 280-290 \mathrm{mOsm} .0 .5 \mathrm{mg} / \mathrm{ml}$ Biocytin.

Post hoc visualization and neuron identification using biocytin labeling was performed as described previously (Horikawa and Armstrong, 1988; de Kock et al., 2007). Image-stacks were created using a 20× air objective using Surveyor software (Objective Imaging Ltd., Stow cum Quy, Cambridge UK available from Chromaphor, Bottrop, Germany) and ImageJ. Pyramidal and nonpyramidal neurons were classified based on morphological and electrophysiological criteria. Pyramidal neurons typically had an input resistance below $100 \mathrm{M} \Omega$; non-pyramidal neurons typically had an input resistance above $100 \mathrm{M} \Omega$ (Tables 2 and 3 ).

\section{SPIKE-TIMING-DEPENDENT PLASTICITY}

Excitatory postsynaptic potential (EPSPs) were evoked every 7 s using an extracellular stimulation electrode positioned at approximately 100-150 $\mu \mathrm{m}$ along the cell's somatodendritic axis (Figures 1A,B). The slope of the initial $2 \mathrm{~ms}$ of the EPSP was analyzed to ensure that the data reflected only the monosynaptic component of each experiment (Froemke et al., 2005; Couey et al., 2007). Synaptic gain was measured as the percent change in EPSP slope when comparing the average in the period $20-30 \mathrm{~min}$ postconditioning to the average baseline EPSP slope. During the induction protocol spike-timings were measured from the onset of the evoked EPSP to the peak of the postsynaptic AP. Mean baseline EPSP slopes were averaged from at least 30 sweeps (with amplitudes in the range of $6-7.5 \mathrm{mV}$ ). During the conditioning period pre-postsynaptic stimulus pairing was repeated $40-50$ times, with a $7 \mathrm{~s}(0.14 \mathrm{~Hz})$ interval between each pairing. Two distinct conditioning protocols were used, two spikes with $10-\mathrm{ms}$ interval (tested in 17 cells) and single spike (tested in two cells). During experiments, cell input resistance was monitored throughout by applying a -10 to -100 pA, 200-500 ms hyperpolarizing pulse at the end of each sweep, additional determination of input resistance was done by extracting an $\mathrm{I}-\mathrm{V}$ curve from each cell, in the beginning of the experiment, after pairing and at the 
Table 2 | Summary table of EPSP kinetic changes in response to tLTP paradigm (two action potential pairing).

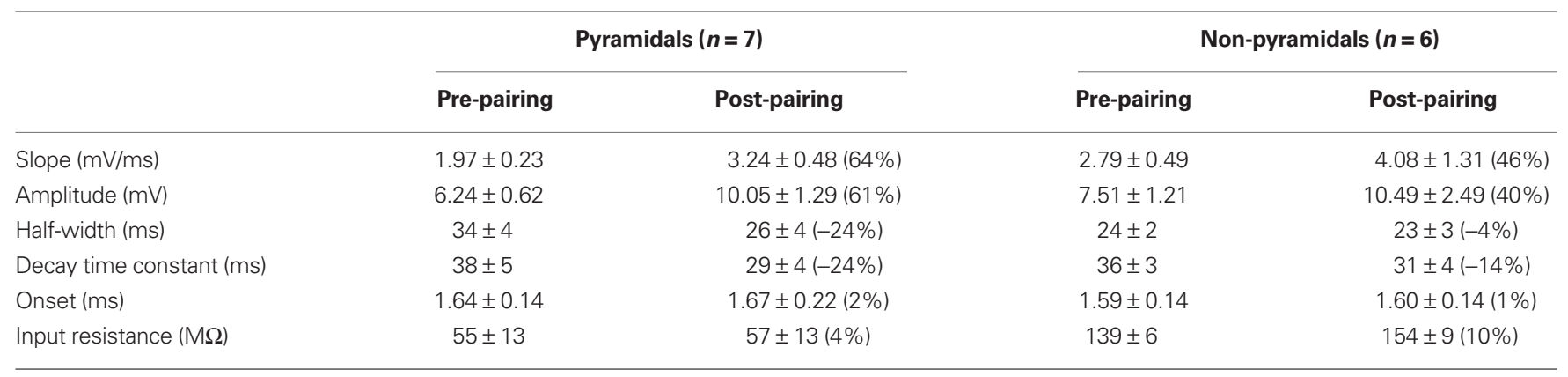

Data presented as mean \pm S.E.M. and percent change between parenthesis.

Table 3 | Summary table of EPSP kinetic changes in response to tLTD paradigm (two action potential pairing).

\begin{tabular}{|c|c|c|c|c|}
\hline & \multicolumn{2}{|c|}{ Pyramidals $(n=3)$} & \multicolumn{2}{|c|}{ Non-pyramidal $(n=1)$} \\
\hline & Pre-pairing & Post-pairing & Pre-pairing & Post-pairing \\
\hline Amplitude (mV) & $6.47 \pm 2.89$ & $3.64 \pm 2.57(-44 \%)$ & $6.76 \pm 1.51$ & $2.83 \pm 1.05(-58 \%)$ \\
\hline Half-width (ms) & $20 \pm 2$ & $12 \pm 4(-40 \%)$ & $30 \pm 3$ & $20 \pm 7(-33 \%)$ \\
\hline Decay time constant (ms) & $25 \pm 3$ & $15 \pm 5(-40 \%)$ & $34 \pm 3$ & $27 \pm 11(-20 \%)$ \\
\hline Input resistance (M $\Omega$ ) & $41 \pm 12$ & $43 \pm 13(4 \%)$ & $155 \pm 3$ & $141 \pm 7(-9 \%)$ \\
\hline
\end{tabular}

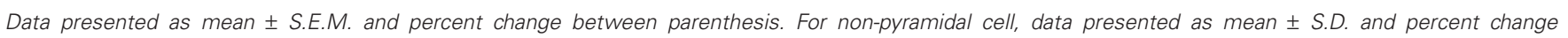
between parenthesis.

end of the recording. Experiments were not included in the analysis if the cell input resistance varied by more than $\pm 30 \%$ during the experiment, which was the case for 13 out of 32 recordings. The $t$-test and the Mann-Whitney $U$ test were used to assess significance on changes in slope for each experiment. Data are given as mean \pm SEM, with $p<0.05$ as minimum for statistical significance. Experiments lasted 20-70 min and where interrupted if the conditions of the patch degenerated or if the cell displayed repeated spiking after potentiation or failures after depression. When recording lasted less than $30 \mathrm{~min}$ (two of 19 recordings included in analysis), the average of baseline was compared to the average of all points in the post-pairing period.

The amplitude of the ADP component of the voltage response was measured from its maxima. The time constant of the decay of the ADP response back to the resting potential, $\tau_{\text {decay }}$, was estimated from the fitting to a single exponential, that is,

$v(t)=\boldsymbol{A} \cdot \exp \left(-\frac{t}{\tau_{\text {decay }}}\right)$

where " $A$ " is a dummy scaling factor.

\section{RESULTS}

Spike-timing-dependent modifications of synapse strength have been found in brains of laboratory animals (Levy and Steward, 1983; Gustafsson et al., 1987; Bell et al., 1997; Magee and Johnston, 1997; Markram et al., 1997, for review see Caporale and Dan, 2008), but it has not been tested directly whether adult human synapses can change strength as a result of the precise timing of pre- and postsynaptic spiking activity. To test this, we made whole-cell recordings from pyramidal neurons and non-pyramidal cells of adult human hippocampus (20-66 years of age) and stimulated glutamatergic inputs by extracellular stimulation (Figure 1). During whole-cell recordings, neurons were labeled with biocytin for post hoc morphological identification. Hippocampal pyramidal neurons and non-pyramidal cells had distinct characteristic morphologies (Figure 1). As described for pyramidal neurons and non-pyramidal cells in human association cortex (Foehring et al., 1991), hippocampal pyramidal neurons, and non-pyramidal cells also showed distinct basic electrophysiological properties (Tables 1-3; Figure 1).

Passive and active cell properties measured in human hippocampal cells were in some aspects comparable to values obtained from rodent cells (Staff et al., 2000; Mercer et al., 2007; Routh et al., 2009). For example pyramidal cell input resistance in rat is $65.6 \pm 4.4 \mathrm{M} \Omega$, in mouse (C57BL/6) is $65.4 \pm 1.7 \mathrm{M} \Omega$, while in human pyramidals it tends to be slightly lower: $49.1 \pm 8.7 \mathrm{M} \Omega$. Input resistance of wide arbor basket cells in rat CA2 is $111.8 \pm 36.7 \mathrm{M} \Omega$, while in human, non-pyramidal cells we found a slightly higher average input resistance of $141.7 \pm 6 \mathrm{M} \Omega$. Pyramidal cell AP amplitude agree well with reported values for rat pyramidal cells (humans: $113.8 \pm 8.0 \mathrm{mV}$; rat: $112.0 \pm 9.0 \mathrm{mV}$ ). Human cells however, have slower rate of rise compared with CA1 rat pyramidal cells. Rat: $381 \pm 18 \mathrm{mV} / \mathrm{ms}$ and human: $231.3 \pm 38.4 \mathrm{mV} / \mathrm{ms}$, but similar 
A

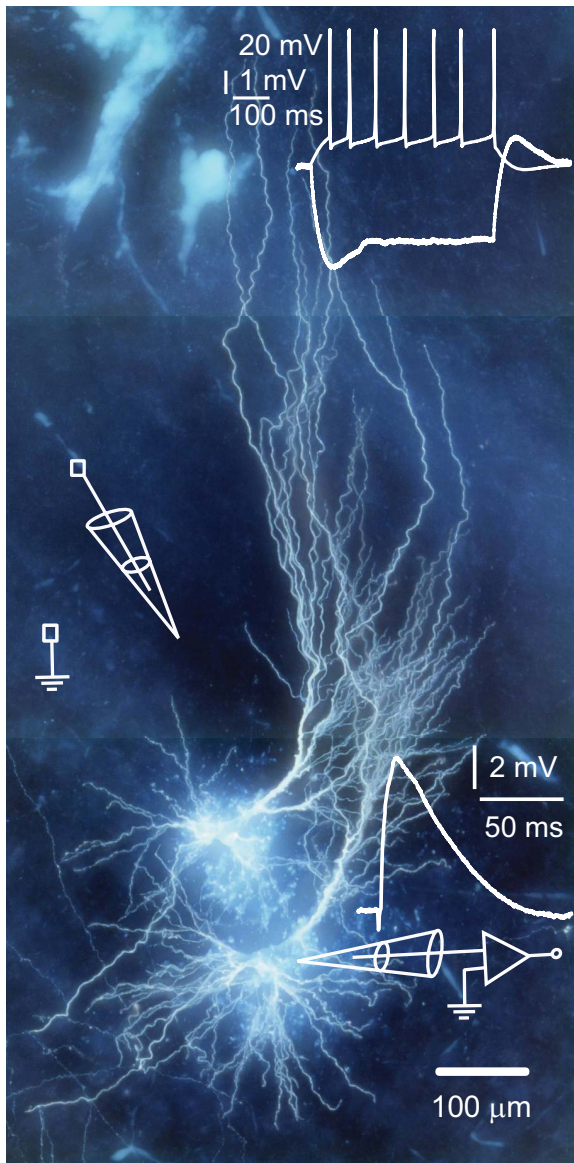

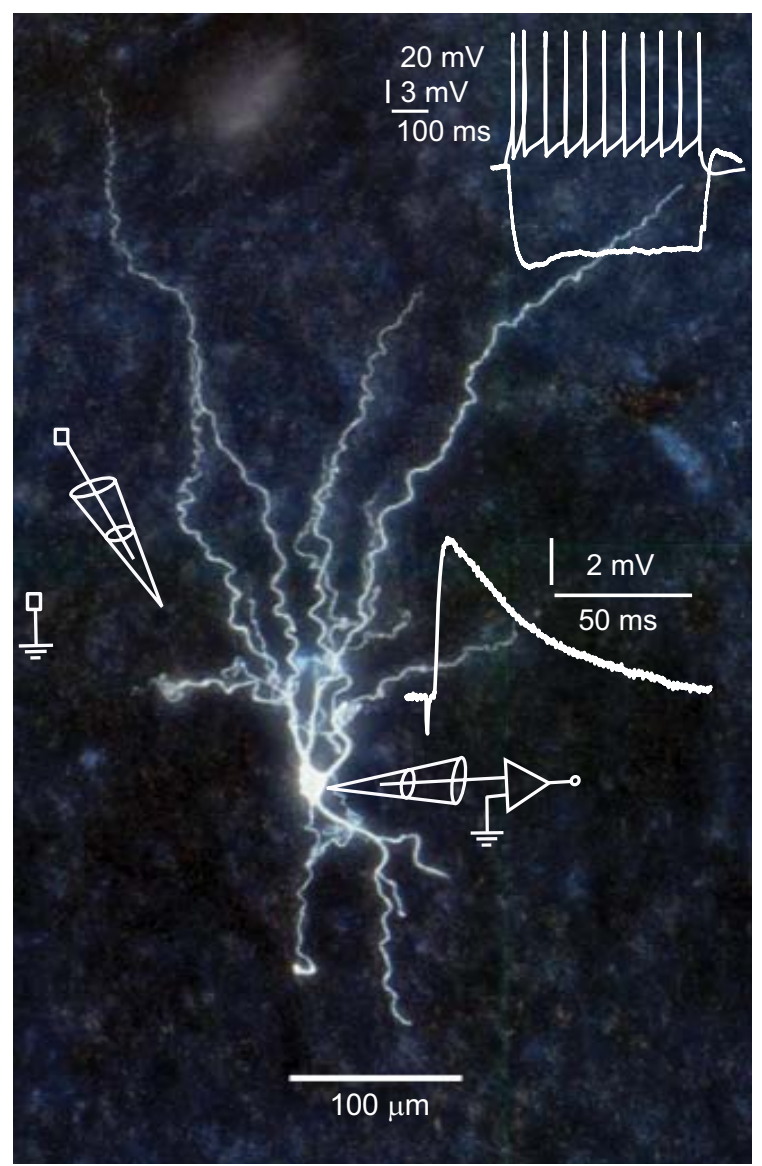

FIGURE 1 | Human hippocampal pyramidal (A) and non-pyramidal neuron (B). Top insets show membrane potential changes in response to step current injections. Different scale bars apply to the hyperpolarizing and depolarizing step. Bottom insets show EPSPs in response to extracellular stimulation.

half-width, rat: $0.93 \pm 0.03 \mathrm{~ms}$ and human $1.1 \pm 0.2 \mathrm{~ms}$, which may indicate possible differences in voltage-gated sodium channel dynamics.

In rodent hippocampus, glutamatergic inputs to pyramidal neurons potentiate when the temporal order of action potential firing is such that spiking of presynaptic fibers is followed by postsynaptic firing (Bi and Poo, 1998; Meredith et al., 2003). The temporal window in which the postsynaptic neuron must spike is $\sim 20 \mathrm{~ms}$ after the presynaptic stimulus for spike-timing-dependent potentiation (tLTP) to occur (Bi and Poo, 1998). To test whether human hippocampal synapses increase strength in response to spike-timing within this positive timing window of $20 \mathrm{~ms}$, we paired presynaptic stimulation with postsynaptic firing with a positive interval of $10 \mathrm{~ms}$ (Figure 2). Since it was reported that in rodent hippocampus the effectiveness of tLTP induction diminishes with age (Meredith et al., 2003), we induced two postsynaptic action potentials (10-ms interval) with each presynaptic stimulus to optimize tLTP induction. After recording 4-5 min of baseline EPSPs, repeated pairing of EPSPs with postsynaptic action potentials (Figure 2A; 40-50 times at $0.14 \mathrm{~Hz}$ ) resulted in a lasting increase of both EPSP amplitude (from $5.47 \pm 1.17 \mathrm{mV}$ at baseline to $9.39 \pm 1.90 \mathrm{mV}$ after pairing, an increase of $72 \%$ ) and slope (from $2.21 \pm 0.39 \mathrm{mV} / \mathrm{ms}$ at baseline to $3.25 \pm 0.79 \mathrm{mV} / \mathrm{ms}$ after pairing, an increase of $65 \%$, $t$-test $p<0.0001$; Figures 2C,D). During the entire recording, other basic electrophysiological parameters such as resting membrane potential and input resistance did not change significantly (Figure 2B; see Section "Materials and Methods"). Pairing pre- and postsynaptic activity at positive intervals $(5-10 \mathrm{~ms})$ resulted in tLTP in both pyramidal neurons $(96 \%, n=3)$ as well as non-pyramidal cells (21\%, $n=4$; Figure 6, Table 2$)$. These results show that excitatory human synapses can show potentiation in response to millisecond timing of pre- and postsynaptic activity.

Reversing the order of presynaptic and postsynaptic action potential firing such that the postsynaptic neuron fires before the presynaptic stimulation induces synaptic depression in rodent hippocampal synapses (Bi and Poo, 1998; Nishiyama et al., 2000; Wittenberg and Wang, 2006). The temporal window for spiketiming synaptic depression (tLTD) in these synapses is around $20 \mathrm{~ms}$. To test whether adult human hippocampal synapses show tLTD in response to negative timing intervals, postsynaptic action potentials were induced $10-80 \mathrm{~ms}$ before the presynaptic stimulus during pairing (Figure 3). In contrast to rodent hippocampal synapses, these intervals induced a robust increase in EPSP amplitude and slope (Figures 3C,D). At $-35 \mathrm{~ms}$ interval, the EPSP amplitude increased from $5.22 \pm 1.13$ to $9.44 \pm 1.13 \mathrm{mV}$ after pairing (an increase of $80 \%$ ) and the slope from $1.57 \pm 0.31 \mathrm{mV} / \mathrm{ms}$ at baseline 

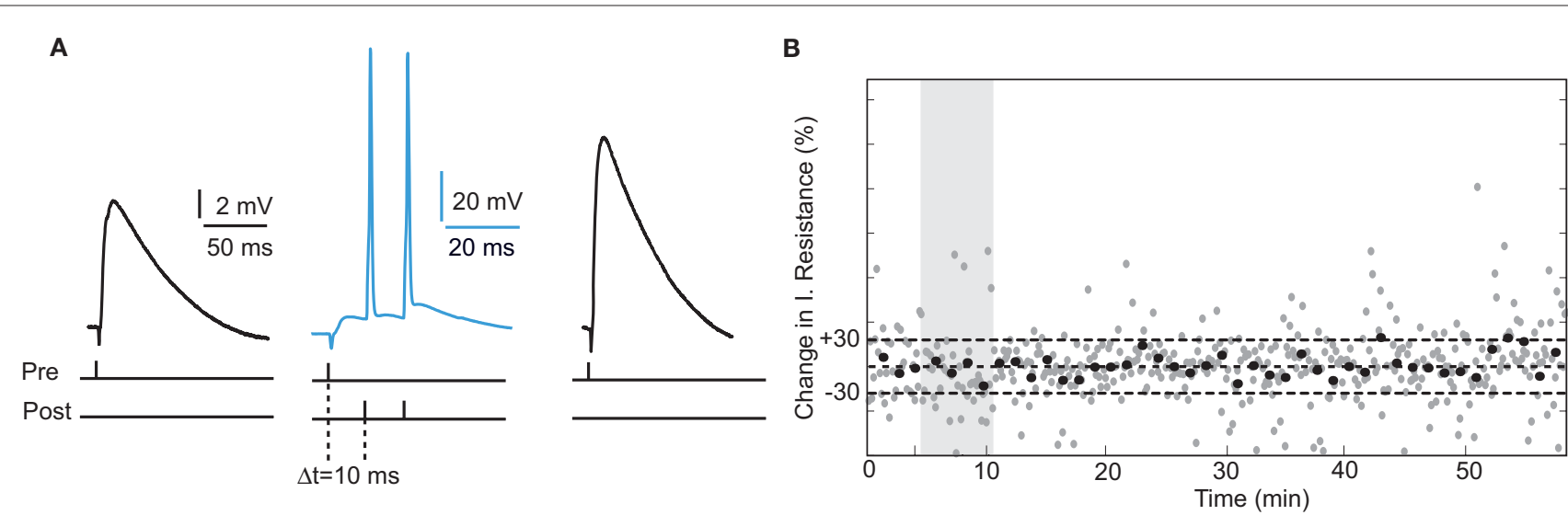

C

D
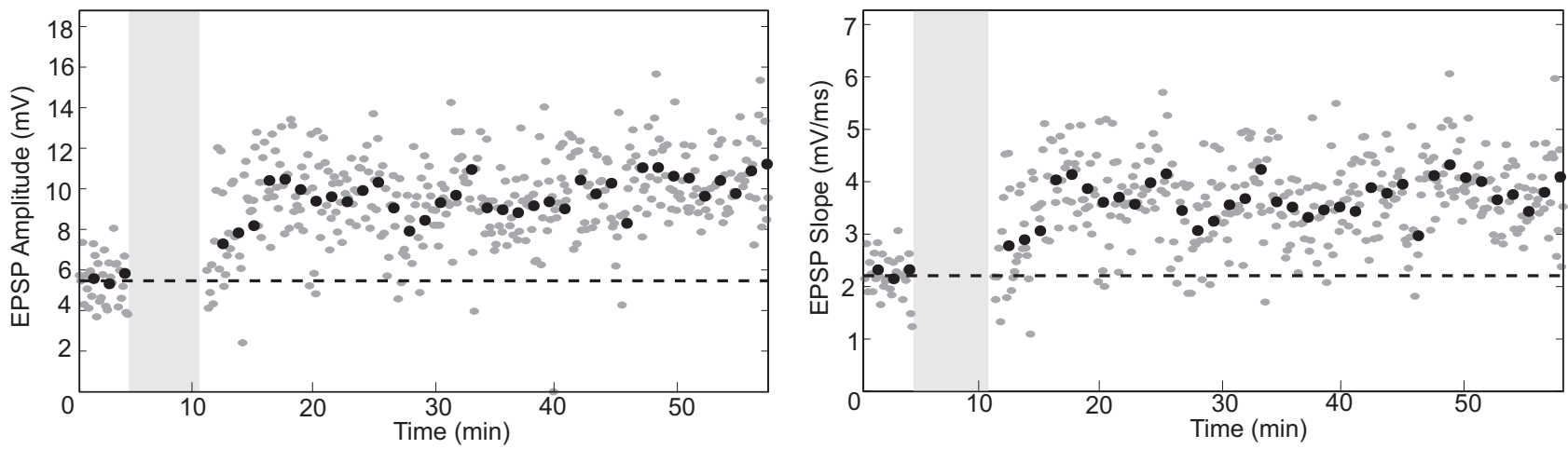

FIGURE 2 | STDP at human excitatory synapses in a hippocampal pyramidal neuron. (A) Schematic representation of the experiment shown in (B-D) with example EPSP and action potential traces. (B) Input resistance calculated from the membrane potential response to a small negative current step delivered through the recording electrode after each EPSP. Grey area indicates the pairing period. (C,D) EPSP amplitude and slope recorded from a hippocampal pyramidal neuron. Same recording as in (B).

to $2.85 \pm 0.34 \mathrm{mV} / \mathrm{ms}$ after pairing (an increase of $81 \%$, $t$-test $p<0.0001$ Figures 3C,D). On average, in pyramidal neurons in which post- before presynaptic timing was applied, synapse strength increased by $58 \%(n=4)$. In non-pyramidal cells, a negative time interval of $-10 \mathrm{~ms}$ induced a $116 \%$ change in EPSP slope and a negative time interval of $-20 \mathrm{~ms}$ induced a $10 \%$ increase in slope (Figure 6). These results indicate that in contrast to rodent hippocampal synapses, adult human hippocampal synapses show tLTP at negative timing intervals up to $-80 \mathrm{~ms}$. The temporal window for tLTP induction covers intervals between -80 and $+10 \mathrm{~ms}$.

Action potentials in human pyramidal neurons showed a prominent after-depolarization (ADP; Figures 3A and 4A; Table 1), possibly reflecting dendritic action potential propagation (Larkum et al., 2001). Dendritic action potential propagation is crucial for tLTP induction (Kampa et al., 2006, 2007; Couey et al., 2007; Fuenzalida et al., 2010). In the recordings with negative timing interval pairings between -10 and $-80 \mathrm{~ms}$, EPSPs coincided with the downward slope of the ADP (Figure 3A), which may have contributed to induction of tLTP. To test whether tLTD would be induced when the EPSP would occur after the membrane potential had returned to baseline, we increased the negative timing interval (Figure 4). When postsynaptic firing was followed by an EPSP after $130 \mathrm{~ms}$, the membrane potential had returned to baseline at the time of presynaptic stimulation (Figure 4A). At this interval, the EPSP amplitude and slope indeed showed a sustained reduction (Figures 4C,D). Both in pyramidal neurons and non-pyramidal cells negative timing intervals between -80 and $-130 \mathrm{~ms}$ induced tLTD. On average, the EPSPs slope was reduced by $-55 \%(n=3)$ in pyramidal neurons. In one non-pyramidal cell, negative timing of $-110 \mathrm{~ms}$ also resulted in a reduction of EPSP slope of $-31 \%$ (Figure 6, Table 2). These findings show that in contrast to rodent hippocampal synapses, the sign of plasticity does not sharply switch around $0 \mathrm{~ms}$ timing in human hippocampal synapses. It switches around $-80 \mathrm{~ms}$.

During maturation of the rodent hippocampus, the effectiveness of postsynaptic spikes to induce tLTP diminishes. Pairing EPSPs with single action potentials fails to induce tLTP at ages beyond 20 days, while pairing EPSPs with a pair of action potentials suffices to induce tLTP at these ages (Meredith et al., 2003). To test whether single spikes paired with EPSPs would induce tLTP in adult human synapses, we applied a timed presynaptic stimulus with a single postsynaptic spike (Figure 5). When the action potential was followed by an EPSP after $75 \mathrm{~ms}$ in a pyramidal neuron, the EPSP slope showed a small but significant increase from $1.34 \pm 0.27 \mathrm{mV} / \mathrm{ms}$ to $1.48 \pm 0.36 \mathrm{mV} / \mathrm{ms}$ after pairing (an increase of $10 \%, t$-test $p<0.05$, Figure 5D). In a non-pyramidal neuron, when the EPSP was followed by a single postsynaptic 

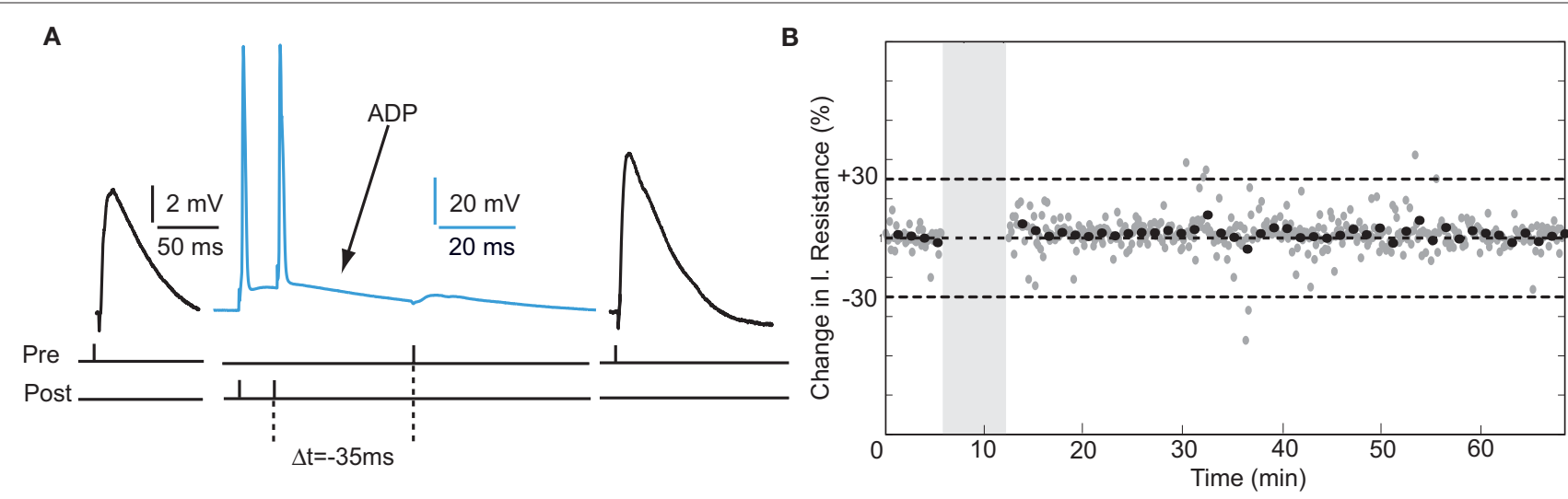

C

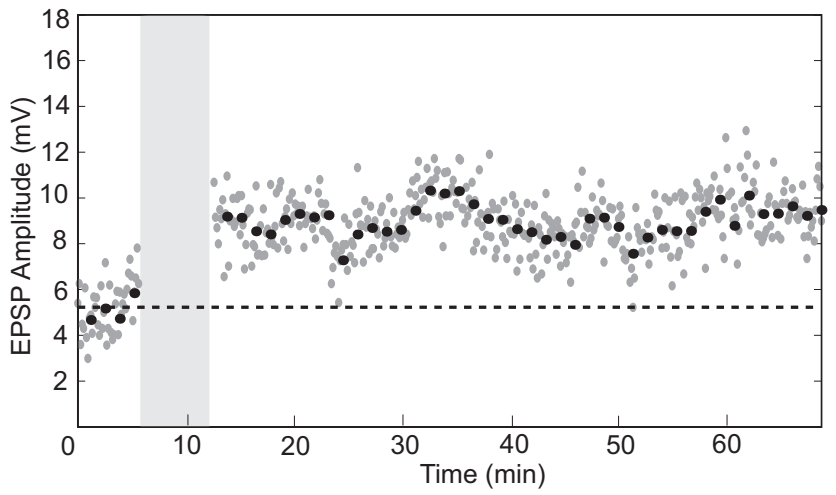

FIGURE 3 | Negative timing intervals at which the postsynaptic neuron fired an action potential before the presynaptic stimulus resulted in tLTP.

(A) Example EPSPs before and after pairing postsynaptic action potential firing
D

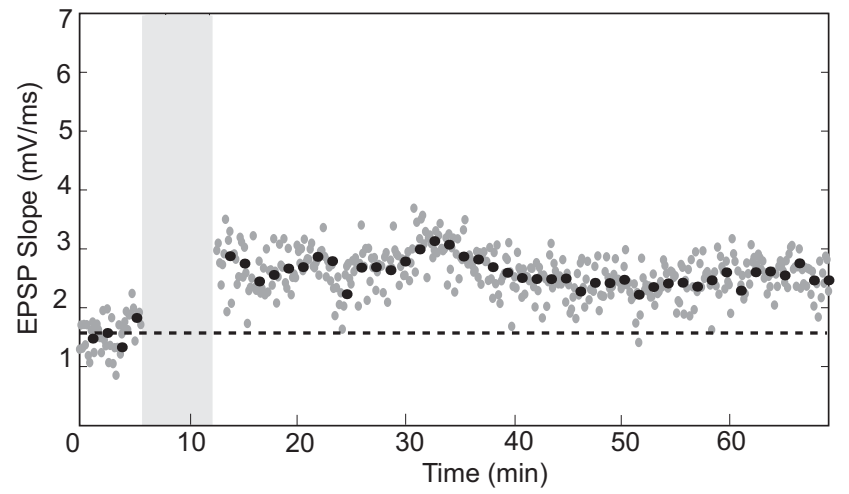

and presynaptic stimulation. (B) Input resistance during the entire recording in (C) and (D). (C,D) EPSP amplitude and slope recorded from a hippocampal pyramidal neuron. action potential after $5 \mathrm{~ms}$, the slope increased by $69 \%$, $t$-test $p<0.0001$. These data may suggest that excitatory synapses in human hippocampus can change strength in response to single postsynaptic action potential pairing. However, given the low number of observations on this induction protocol a firm conclusion on this issue awaits further testing.

In rodents and other species, the size and shape of the time windows in which positive and negative synaptic weight changes occur vary for different brain regions (Bi and Poo, 2001; Caporale and Dan, 2008). Excitatory synapses in the human hippocampus showed a wide temporal window for STDP (Figure 6). Pairing intervals between -80 and $+10 \mathrm{~ms}$ induced robust increases in synaptic weight, showing that tLTP was induced at positive and negative timing intervals. Negative timing intervals between -130 and $-80 \mathrm{~ms}$ induced substantial tLTD. Our findings show that both for excitatory synapses on pyramidal neurons as well as on non-pyramidal neurons, synapse strength could be altered bi-directionally by spike-timing.

\section{DISCUSSION}

In this study, we directly tested in whole-cell recordings from human hippocampal neurons whether human synapses can alter strength in response to millisecond timing of pre- and postsynaptic activity and what timing rules determine the sign of plasticity. Our main findings are: (1) Adult human hippocampal synapses can alter synapse strength in response to pairing EPSPs with postsynaptic burst activity and possibly also with single postsynaptic action potentials. (2) In contrast to rodent hippocampal synapses, the sign of plasticity does not sharply switch around $0 \mathrm{~ms}$ timing. Instead, both positive timing intervals, in which presynaptic firing preceded the postsynaptic action potential up to $20 \mathrm{~ms}$, and negative timing intervals, in which postsynaptic firing preceded presynaptic activity down to $-80 \mathrm{~ms}$, induce tLTP. (3) Negative timing intervals between -80 to $-130 \mathrm{~ms}$ induce tLTD.

In rodent hippocampus, the rules for induction of STDP change over development (Meredith et al., 2003). A developmental shift occurs in the effectiveness of a single-spike pairing protocol at inducing tLTP. In young hippocampus, repeated pairing of presynaptic activity with a single postsynaptic action potential suffices to induce tLTP, whereas in older rodents a postsynaptic burst of action potentials is necessary to induce synaptic strengthening (Meredith et al., 2003). Blocking GABAergic inhibition with bicuculline rescued the effectiveness of single-spike pairing in inducing tLTP in older animals, which suggests that rules for STDP are affected by a developmental maturation of GABAergic inhibition in the rodent hippocampus (Meredith et al., 2003). In pyramidal neurons, somatic action 

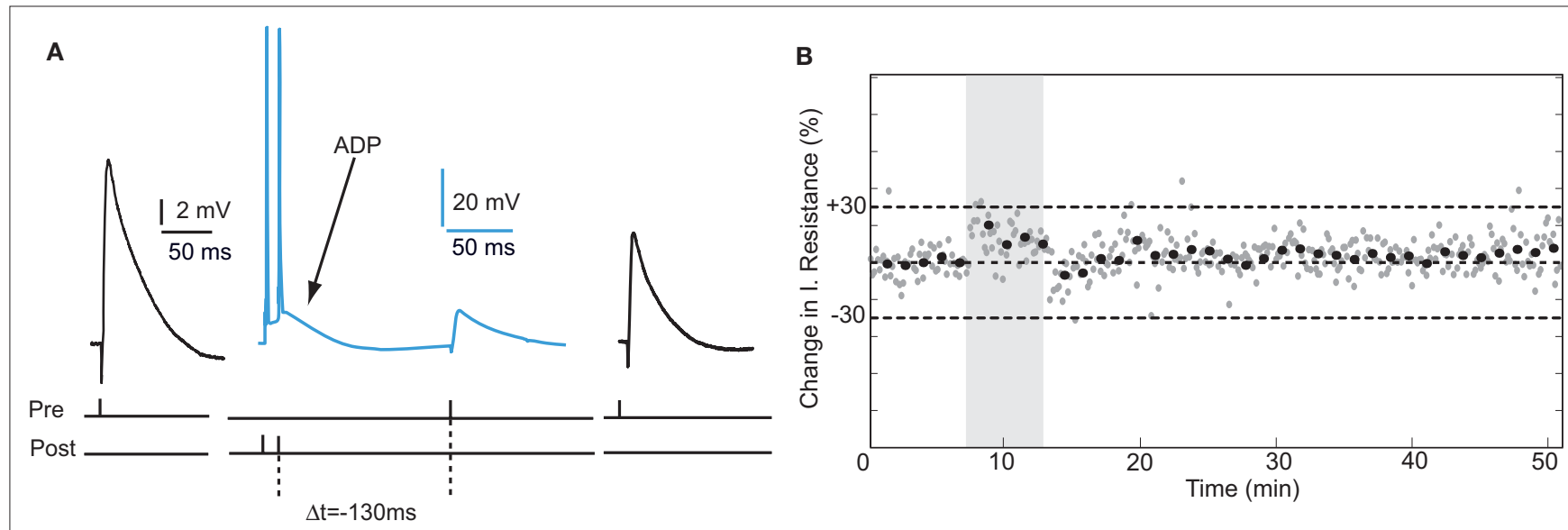

C

D
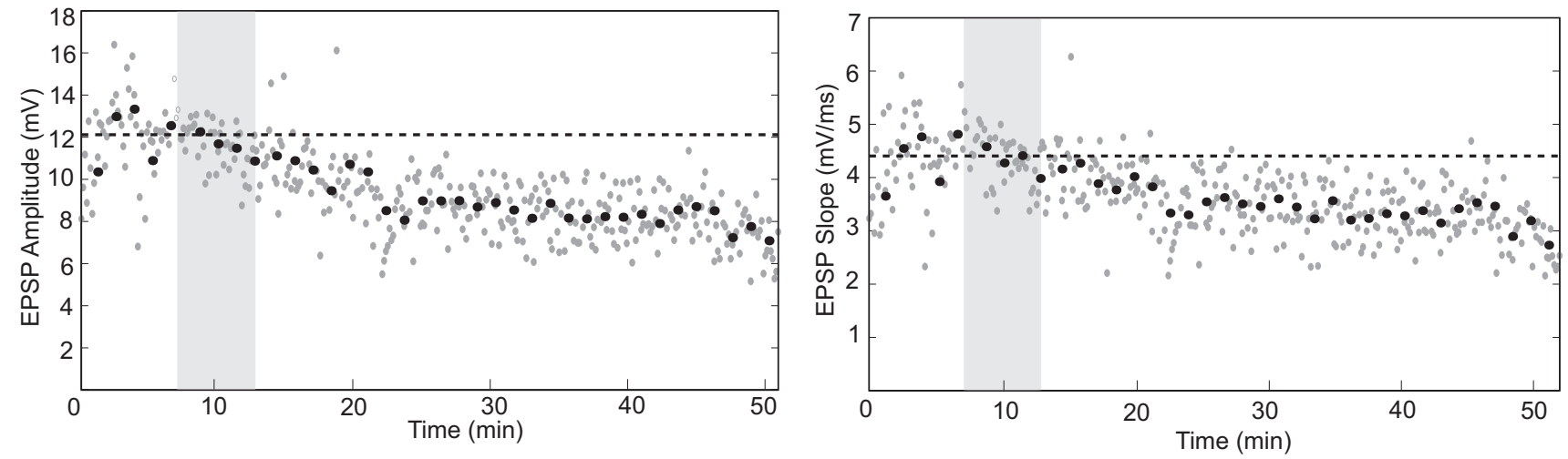

FIGURE $\mathbf{4}$ | tLTD is induced at negative timing intervals between $-\mathbf{8 0}$ and $\mathbf{- 1 3 0} \mathbf{~ m s . ~ ( A ) ~ S c h e m a t i c ~ r e p r e s e n t a t i o n ~ o f ~ t h e ~ e x p e r i m e n t ~ w i t h ~ e x a m p l e ~ t r a c e s . ~ ( B ) ~ I n p u t ~}$ resistance during the entire recording period. (C,D) Example of EPSP amplitude and slope recorded from a hippocampal pyramidal neuron. Same recording as in (B).

potentials back-propagate deep into the dendritic tree and activate voltage-gated calcium channels in proximal and distal parts of dendrites, inducing substantial amounts of calcium influx in dendrites and dendritic spines that can trigger synaptic strength changes (Yuste and Denk, 1995; Magee and Johnston, 1997; Stuart et al., 1997; Koester and Sakmann, 1998). Dendritic back-propagation of action potentials is under GABAergic inhibitory control (Tsubokawa and Ross, 1996). Coincident activation of GABAergic inputs reduces dendritic action potential amplitude and dendritic calcium signals associated with the action potential, which may explain the loss of effectiveness of singlespike pairing in inducing tLTP in older rodent hippocampus. In adult human hippocampus of 20- to 66-years old, repeated pairing of presynaptic activity with a single postsynaptic action potential did induce tLTP. This may suggest that differences may exist between human and rodent adult hippocampal dendrites either in the effectiveness of action potential propagation or in the effectiveness of postsynaptic calcium to trigger the molecular machinery for synapse strengthening. Despite the absence of epileptiform activity, brain slices used in our study were removed from brains of epileptic patients, where GABA might have a depolarizing effect (Dzhala and Staley, 2003; Rheims et al., 2008). It is valid to consider the influence that GABAergic input, potentially recruited via extracellular stimulation, might have on the time window for STDP induction.
The size and shape of the temporal STDP windows in which positive and negative synapse strength changes can vary for different brain regions (Caporale and Dan, 2008). In rodent hippocampus, the window for synaptic modification is restricted to about $40 \mathrm{~ms}$ (Bi and Poo, 1998; Debanne et al., 1998; Nishiyama et al., 2000; Wittenberg and Wang, 2006) and a sharp switch of the direction of synaptic change exists at 0 -ms timing interval. In adult human hippocampus we did not observe a sharp change of sign of plasticity; positive as well as negative timing intervals induce tLTP. Increases in synapse strength at negative timing intervals have been observed at excitatory synapses onto GABAergic Purkinje-like neurons in electric fish (Bell et al., 1997). Negative timing intervals up to $-50 \mathrm{~ms}$ resulted in tLTP. Increases in synapse strength in response to negative timing intervals have also been observed in excitatory synapses at distal dendritic locations in neocortex. In neocortex, the shape of the temporal STDP windows depends on dendritic location of synapses (Froemke et al., 2005). In layer 5 pyramidal neurons, proximal and distal synapses exhibit a progressive distance-dependent shift in the timing requirements of the induction of tLTP and tLTD (Letzkus et al., 2006). Distal synapses potentiate when the EPSP arrives after the onset of an $\mathrm{AP}$, in contrast to the timing requirements of proximal synapses at the same dendrites. Most likely during pairing at $-10 \mathrm{~ms}$, distal 


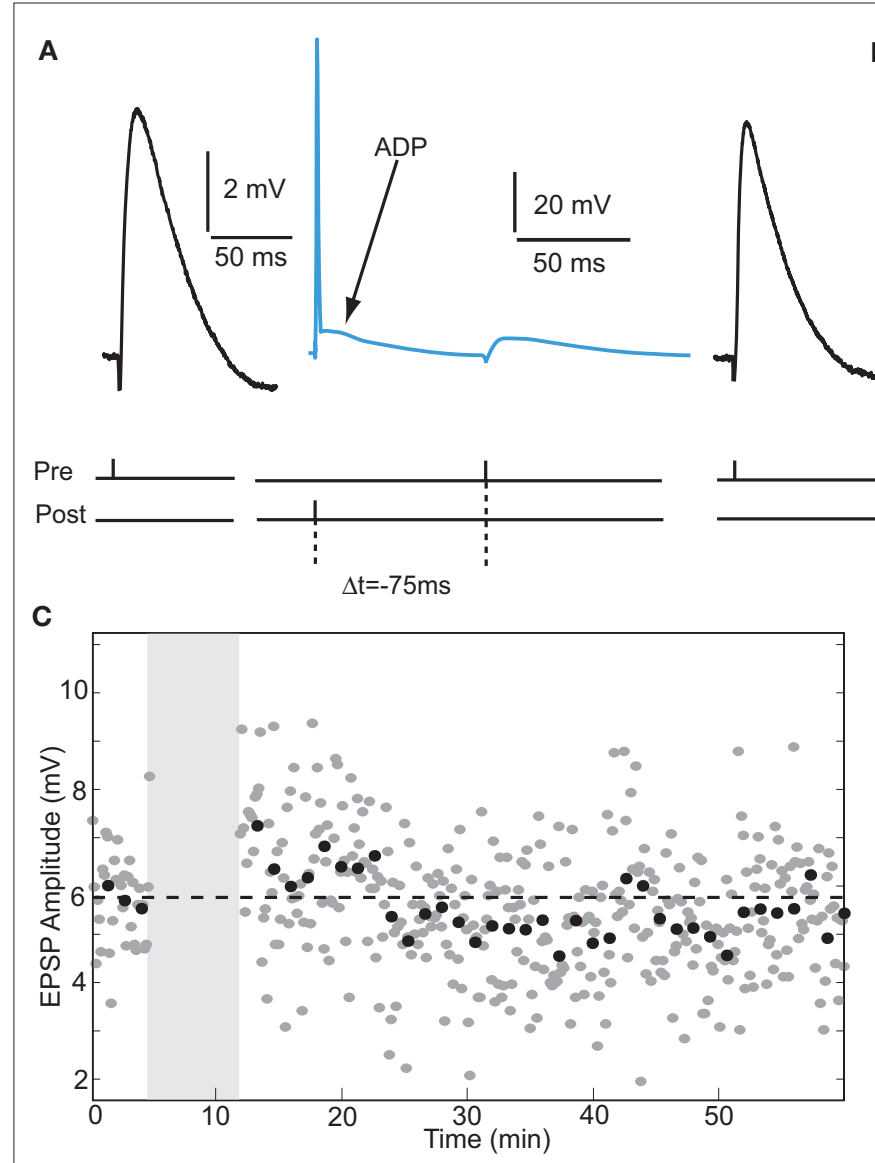

B

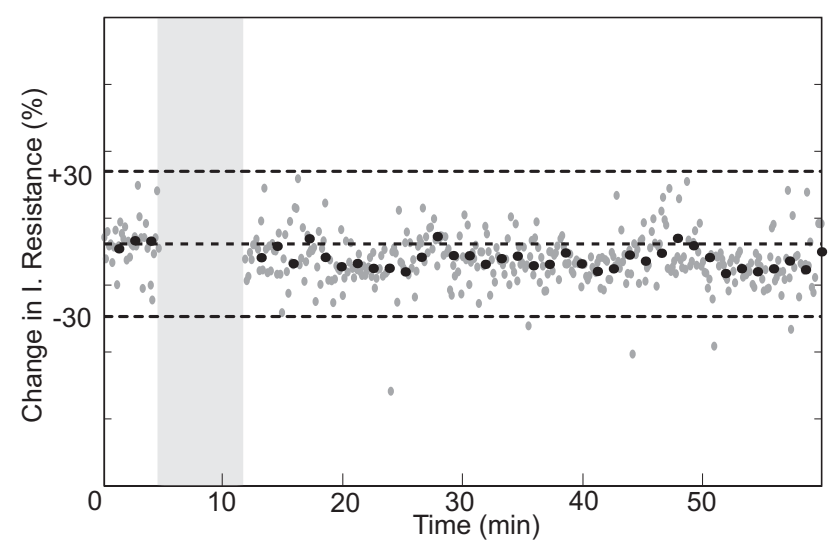

D

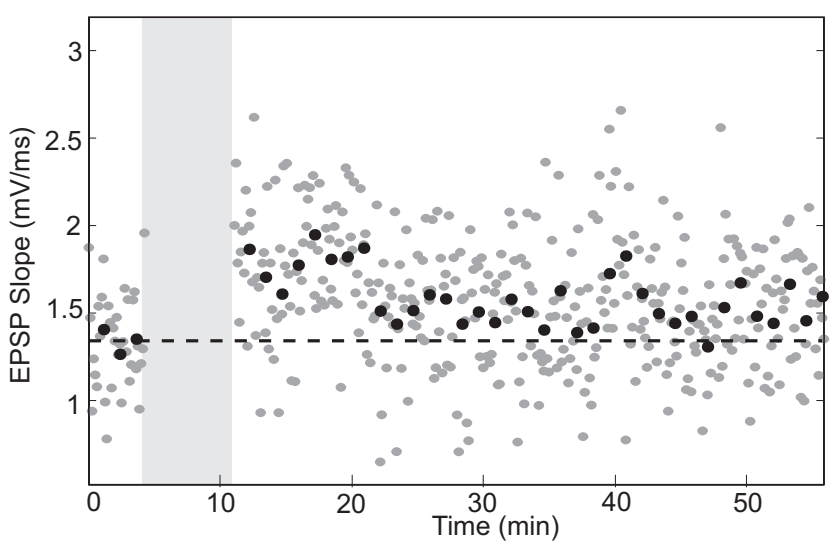

FIGURE 5 | Single postsynaptic action potentials paired with EPSPs induce STDP in adult human hippocampal neurons. (A) Schematic representation of the experiment with example traces. (B) Input resistance during the entire recording period. (C,D) Single-spike pairing did not alter EPSP amplitude, but induced a small but significant change in slope.

EPSPs coincide with dendritic calcium dynamics induced by the backpropagating action potential (Letzkus et al., 2006; Cornelisse et al., 2007). To prevent variability in the amount of synaptic gain due to spatial dependence of the stimulation site (Sjöström and Häusser, 2006), distance between the recording and stimulation electrodes was carefully controlled in the present study, as described in the Section "Materials and methods". Here, we observed that in human hippocampal synapses a wide window for tLTP exists. Possibly timing delays due to propagation of action potentials in extensive dendritic trees could play a role in determining the timing windows. Alternatively, species differences in synapse dynamics may explain wide STDP temporal window in human synapses.

Whether similar mechanisms as for rat neocortical distal synapses underlie tLTP induction at negative timing intervals in human hippocampal synapses is not clear. Human hippocampal pyramidal neurons did show a prominent ADP, which may result from dendritic action potential propagation. At negative timing intervals between 0 and $-80 \mathrm{~ms}$, the EPSP coincided with the falling flank of the ADP, possibly indicating that the EPSP coincided with calcium dynamics induced by the dendritic action potential. Similar mechanisms as in distal neocortical layer 5 synapses may extend the tLTP window to negative timing intervals in human synapses. However, important differences also exist. In contrast to the human synapses, for both synapses on Purkinje-like neurons and rat neocortical distal synapses there was a sharp switch of the sign of plasticity at 0 -ms timing interval. Uncovering the mechanisms underlying the tLTP window in human synapses requires further experimental testing.

In rodent hippocampus, the capacity for synaptic depression in synapses declines with age (Dudek and Bear, 1993; Bear and Abraham, 1996). In mouse somatosensory cortex, tLTD induced by a negative timing order in which the postsynaptic neuron fires before the EPSP disappears with age (Banerjee et al., 2009). At ages up to postnatal day 25 , negative timing intervals of -10 to $-15 \mathrm{~ms}$ elicited robust tLTD. At ages beyond 25 days, these timing intervals did not change synaptic strength at all. In adult human hippocampus we find that negative timing intervals between -130 and -80 ms elicit robust tLTD. What the mechanisms are can explain the observation that the timing window lies around $-100 \mathrm{~ms}$ is currently not known. However, at these intervals, the ADP that follows the action potential has subsided back to baseline by the time the EPSP occurs, which may indicate that at this time the EPSP does not coincide with dendritic calcium dynamics. Our findings do show that human synapses can change bi-directionally depending on spike-timing. 


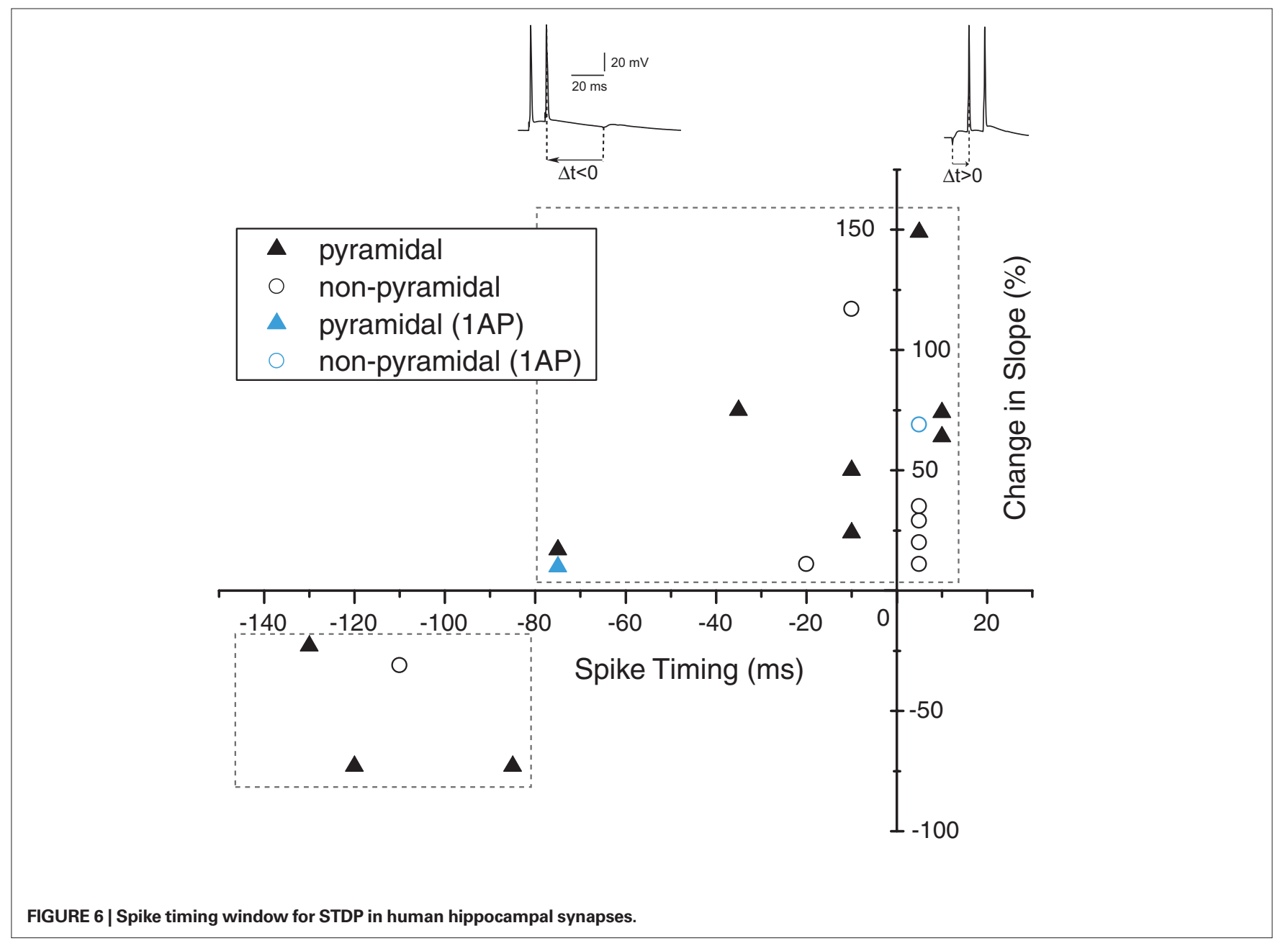

Do Hebb's predictions hold for human synapses (Hebb, 1949)? He proposed that neurons that fire together, also wire together. With the finding that the sign of plasticity depends on the order of presynaptic and postsynaptic firing (Bell et al., 1997; Magee and Johnston, 1997; Markram et al., 1997) it has been emphasized that temporal specificity is a central feature of Hebb's postulate ( $\mathrm{Bi}$ and Poo, 2001). Indeed, in rodent hippocampus with a temporal window of $20 \mathrm{~ms}$ for tLTP (Bi and Poo, 1998; Debanne et al., 1998; Nishiyama et al., 2000; Wittenberg and Wang, 2006), neurons that fire together will only wire together if pre- and postsynaptic spike timing is tightly correlated. In human synapses it seems that the timing that is necessary to wire together is less strict. The neurons we recorded from showed tLTP in a wide temporal window of about $100 \mathrm{~ms}$. This may be an underestimation since we did not test intervals outside -130 and $+10 \mathrm{~ms}$ in this study. Different timing windows have been found in different brain areas (Caporale and Dan, 2008). Asymmetric anti-Hebbian STDP, or the depression of an EPSP that occurs if a presynaptic spike follows an increase in the probability of a postsynaptic spike during pairing and reverses into potentiation if the pairing order is reversed (Roberts and Bell, 2002; Zilberter et al., 2009), has been observed in a cell-specific manner in the dorsal cochlear nucleus of the rodent brainstem (Tzounopoulos et al., 2004). The mechanistic basis for a wide temporal window in human hippocampus is at this point not clear, but dendritic calcium dynamics induced by dendritic action potential backpropagation may be involved. If this is the case, and EPSPs coinciding with dendritic calcium dynamics induced by dendritic firing can induce tLTP, then a less strict interpretation of Hebb's theory still applies to human synapses. A wider temporal window for strengthening of synapses in the human brain may allow for the association of larger variety of events with less emphasis on the temporal order. In conclusion, we find that the temporal window for STDP in adult human hippocampal synapses differs from rodent hippocampus, but that the core principles of spike-timing-dependent plasticity apply also to human synapses.

\section{ACKNOWLEDGMENTS}

We thank Hans Lodder and Brendan Lodder for excellent technical assistance, Dr. Rhiannon Meredith and Dr. Diana Rotaru for discussions, Dr. Philip de Witt Hamer for assistance with human brain tissue handling, and Prof. Menno Witter and Prof. Tamás Freund for advice on hippocampal and neuronal anatomy. Funding for this work was provided by grants from NWO (917.76.360), Neuroscience Campus Amsterdam, VU University board (Stg VU-ERC) and Neurobsik to Huibert D. Mansvelder. 


\section{REFERENCES}

Banerjee, A., Meredith, R. M., RodriguezMoreno, A., Mierau, S. B., Auberson, Y. P., and Paulsen, O. (2009). Double dissociation of spike timing-dependent potentiation and depression by subunit-preferring NMDA receptor antagonists in mouse barrel cortex. Cereb. Cortex 19, 2959-2969.

Bear, M. F., and Abraham, W. C. (1996). Long-term depression in hippocampus. Annu. Rev. Neurosci. 19, 437-462.

Beck, H., Goussakov, I. V., Lie, A., Helmstaedter, C., and Elger, C. E. (2000). Synaptic plasticity in the human dentate gyrus. J. Neurosci. 20, 7080-7086.

Bell, C. C., Han, V. Z., Sugawara, Y., and Grant, K. (1997). Synaptic plasticity in a cerebellum-like structure depends on temporal order. Nature 387, 278-281.

Bi, G., and Poo, M. (2001). Synaptic modification by correlated activity: Hebb's postulate revisited. Annu. Rev. Neurosci. 24, 139-166.

Bi, G. Q., and Poo, M. M. (1998). Synaptic modifications in cultured hippocampal neurons: dependence on spike timing, synaptic strength, and postsynaptic cell type. J. Neurosci. 18, 10464-10472.

Bliss, T. V., and Lomo, T. (1973). Longlasting potentiation of synaptic transmission in the dentate area of the anaesthetized rabbit following stimulation of the perforant path. J. Physiol. (Lond.) 232, 331-356.

Bureau, I., von Saint Paul, F., and Svoboda, K. (2006). Interdigitated paralemnis$\mathrm{cal}$ and lemniscal pathways in the mouse barrel cortex. PLoS Biol. 4:e382. doi:10.1371/journal.pbio.0040382.

Caporale, N., and Dan, Y. (2008). Spike timing-dependent plasticity: a Hebbian learning rule. Annu. Rev. Neurosci. 31, 25-46.

Chen, W. R., Lee, S., Kato, K., Spencer, D. D., Shepherd, G. M., and Williamson, A. (1996). Long-term modifications of synaptic efficacy in the human inferior and middle temporal cortex. Proc. Natl. Acad. Sci. USA 93, 8011-8015.

Cooke, S. F., and Bliss, T. V. P. (2006). Plasticity in the human central nervous system. Brain 129, 1659-1673.

Cornelisse, L. N., van Elburg, R. A., Meredith, R. M., Yuste, R., and Mansvelder, H. D. (2007). High speed two-photon imaging of calcium dynamics in dendritic spines: consequences for spine calcium kinetics and buffer capacity. PLoS One 2:e1073 doi:10.1371/journal.pone.0001073.

Couey, J. J., Meredith, R. M., Spijker, S., Poorthuis, R., Smit, A. B., Brussaard,
A. B., and Mansvelder, H. D. (2007). Distributed network actions by nicotine increase the threshold for spike-timing-dependent plasticity in prefrontal cortex. Neuron 54, 73-87.

de Kock, C. P., Bruno, R. M., Spors, H., and Sakmann, B. (2007). Layer- and celltype-specific suprathreshold stimulus representation in rat primary somatosensory cortex. J. Physiol. (Lond.) 581, 139-154.

Debanne, D., Gahwiler, B. H., and Thompson, S. M. (1998). Long-term synaptic plasticity between pairs of individual CA3 pyramidal cells in rat hippocampal slice cultures. J. Physiol. (Lond.) 507(Pt 1), 237-247.

Dudek, S. M., and Bear, M. F. (1993). Bidirectional long-term modification of synaptic effectiveness in the adult and immature hippocampus. J. Neurosci. 13, 2910-2918.

Dzhala, V. I., and Staley, K. J. (2003). Excitatory actions of endogenously released GABA contribute to initiation of ictal epileptiform activity in the developing hippocampus. J. Neurosci. 23, 1840-1846.

Foehring, R. C., Lorenzon, N. M., Herron, P., and Wilson, C. J. (1991). Correlation of physiologically and morphologically identified neuronal types in human association cortex in vitro. J. Neurophysiol. 66, 1825-1837.

Froemke, R. C., Poo, M. M., and Dan, Y. (2005). Spike-timing-dependent synaptic plasticity depends on dendritic location. Nature 434, 221-225.

Fuenzalida, M., Fernandez de Sevilla, D. Couve, A., and Buno, W. (2010). Role of AMPA and NMDA receptors and back-propagating action potentials in spike timing-dependent plasticity. $J$. Neurophysiol. 103, 47-54.

Gustafsson, B., Wigstrom, H., Abraham, W. C., and Huang, Y. Y. (1987). Long-term potentiation in the hippocampus using depolarizing current pulses as the conditioning stimulus to single volley synaptic potentials. J. Neurosci. 7, 774-780.

Hebb, D. (1949). The Organization of Behavior. New York: John Wiley.

Horikawa, K., and Armstrong, W. E. (1988). A versatile means of intracellular labeling: injection of biocytin and its detection with avidin conjugates. $J$. Neurosci. Methods 25, 1-11.

Kampa, B. M., Letzkus, J. J., and Stuart, G. J. (2006). Requirement of dendritic calcium spikes for induction of spiketiming-dependent synaptic plasticity. J. Physiol. (Lond.) 574, 283-290.

Kampa, B. M., Letzkus, J. J., and Stuart, G. J. (2007). Dendritic mechanisms controlling spike-timing-dependent synaptic plasticity. Trends Neurosci. 30, 456-463.
Koester, H. J., and Sakmann, B. (1998) Calcium dynamics in single spines during coincident pre- and postsynaptic activity depend on relative timing of back-propagating action potentials and subthreshold excitatory postsynaptic potentials. Proc. Natl. Acad. Sci. USA 95, 9596-9601.

Larkum, M. E., Zhu, J. J., and Sakmann, B. (2001). Dendritic mechanisms underlying the coupling of the dendritic with the axonal action potential initiation zone of adult rat layer 5 pyramidal neurons. J. Physiol. 533 , 447-466.

Letzkus, J. J., Kampa, B. M., and Stuart, G. J. (2006). Learning rules for spike timing-dependent plasticity depend on dendritic synapse location. $J$. Neurosci. 26, 10420-10429.

Letzkus, J. J., Kampa, B. M., and Stuart, G. J. (2007). Does spike timing-dependent synaptic plasticity underlie memory formation? Clin. Exp. Pharmacol. Physiol. 34, 1070-1076.

Levy, W. B., and Steward, O. (1983) Temporal contiguity requirements for long-term associative potentiation/depression in the hippocampus. Neuroscience 8, 791-797.

Magee, J. C., and Johnston, D. (1997) A synaptically controlled, associative signal for Hebbian plasticity in hippocampal neurons. Science 275 , 209-213.

Markram, H., Lubke, J., Frotscher, M. and Sakmann, B. (1997). Regulation of synaptic efficacy by coincidence of postsynaptic APs and EPSPs. Science 275, 213-215.

Mercer, A., Trigg, H. L., and Thomson, A. M. (2007). Characterization of neurons in the CA2 subfield of the adult rat hippocampus. J. Neurosci. 27, 7329-7338.

Meredith, R. M., Floyer-Lea, A. M., and Paulsen, O. (2003). Maturation of long-term potentiation induction rules in rodent hippocampus: role of GABAergic inhibition. J. Neurosci.23, 11142-11146

Meredith, R. M., Holmgren, C. D. Weidum, M., Burnashev, N., and Mansvelder, H. D. (2007). Increased threshold for spike-timing-dependent plasticity is caused by unreliable calcium signaling in mice lacking fragile X gene FMR1. Neuron 54, 627-638.

Nishiyama, M., Hong, K., Mikoshiba, K., Poo, M.-M., and Kato, K. (2000) Calcium stores regulate the polarity and input specificity of synaptic modification. Nature 408 , 584-588.

Rheims, S., Represa, A., Ben-Ari, Y. and Zilberter, Y. (2008). Layerspecific generation and propagation of seizures in slices of developing neocortex: role of excitatory GABAergic synapses. $J$ Neurophysiol. 100, 620-628.

Roberts, P.D., and Bell, C. C. (2002). Spike timing dependent synaptic plasticity in biological systems. Biol. Cybern. 87, 392-403.

Routh, B. N., Johnston, D., Harris, K., and Chitwood, R. A. (2009). Anatomical and electrophysiological comparison of CA1 pyramidal neurons of the rat and mouse. J. Neurophysiol. 102 2288-2302.

Sjöström, P. J., Häusser, M. (2006). A cooperative switch determines the sign of synaptic plasticity in distal dendrites of neocortical pyramidal neurons. Neuron 51, 227-238.

Staff, N. P., Jung, H.Y., Thiagarajan, T., Yao, M., and Spruston, N. (2000). Resting and active properties of pyramidal neurons in subiculum and CA1 of rat hippocampus. J. Neurophysiol. 84 , 2398-2408.

Stefan, K., Kunesch, E., Cohen, L. G., Benecke, R., and Classen, J. (2000) Induction of plasticity in the human motor cortex by paired associative stimulation. Brain 123, 572-584.

Stuart, G., Spruston, N., Sakmann, B., and Hausser, M. (1997). Action potential initiation and backpropagation in neurons of the mammalian CNS. Trends Neurosci. 20, 125-131.

Tsubokawa, H., and Ross, W. N. (1996). IPSPs modulate spike backpropagation and associated $\left[\mathrm{Ca}^{+}\right]$i changes in the dendrites of hippocampal CA1 pyramidal neurons. J. Neurophysiol. 76, 2896-2906.

Tzounopoulos, T., Kim, Y., Oertel, D., and Trussell, L. O. (2004). Cell-specific, spike timing-dependent plasticities in the dorsal cochlear nucleus. Nat. Neurosci. 7, 719-725.

Whitlock, J. R., Heynen, A. J., Shuler, M. G., and Bear, M. F. (2006). Learning induces long-term potentiation in the hippocampus. Science 313 1093-1097.

Wittenberg, G. M., and Wang, S. S. (2006) Malleability of spike-timing-dependent plasticity at the CA3-CA1 synapse. $J$ Neurosci. 26, 6610-6617.

Wolters, A., Sandbrink, F., Schlottmann, A., Kunesch, E., Stefan, K., Cohen, L. G., Benecke, R., and Classen, J. (2003). A temporally asymmetric Hebbian rule governing plasticity in the human motor cortex. J. Neurophysiol. 89 2339-2345.

Wolters, A., Schmidt, A., Schramm, A., Zeller, D., Naumann, M., Kunesch, E., Benecke, R., Reiners, K., and Classen, J. (2005). Timing-dependent plasticity in human primary somatosensory cortex. J. Physiol. (Lond.) 565, 1039-1052. 
Yuste, R., and Denk, W. (1995). Dendritic spines as basic functional units of neuronal integration. Nature 375, 682-684.

Zilberter, M., Holmgren, C., Shemer, I., Silberberg, G., Grillner, S., Harkany, T., and Zilberter, Y. (2009). Input specificity and dependence of spike timing-dependent plasticity on preceding postsynaptic activity at unitary connections between neocortical layer 2/3 pyramidal cells. Cereb. Cortex 19 , 2308-2320.

Conflict of Interest Statement: The authors declare that the research was conducted in the absence of any commercial or financial relationships that could be construed as a potential conflict of interest.
Received: 01 February 2010; paper pending published: 16 February 2010; accepted: 17 May 2010; published online: 02 July 2010. Citation: Testa-Silva G, Verhoog MB, Goriounova NA, Loebel A, Hjorth JJJ, Baayen JC, de Kock CPJ and Mansvelder HD (2010) Human synapses show a wide temporal window for spike-timing-dependent plasticity. Front. Syn. Neurosci. 2:12. doi: 10.3389/fnsyn.2010.00012
Copyright (c) 2010 Testa-Silva, Verhoog, Goriounova, Loebel, Hjorth, Baayen, de Kock and Mansvelder. This is an open-access article subject to an exclusive license agreement between the authors and the Frontiers Research Foundation, which permits unrestricted use, distribution, and reproduction in any medium, provided the original authors and source are credited. 